\title{
ENHANCEMENT OF INFORMATION AND COMMUNICATIONS TECHNOLOGIES (ICTS) EDUCATION THROUGH THE DEVELOPMENT OF INSTRUCTION DELIVERY EXPERT SYSTEM FOR TEACHERS (IDEST)
}

\author{
I. E. BASSEY, E. E. UMOH AND D. O. EGETE
}

(Received 18, May 2009; Revision Accepted 4, November 2009)

\begin{abstract}
Technology, especially that offered by Information and Communications Technologies (ICTs), brought about by computer technology, has become one of the most popular avenues for transformation in every aspect of human endeavour. Information and Communications Technologies had equally reformed and transformed the world of education by presenting both learners and instructors with spices of motivators onto effective learning and teaching possibilities. This paper therefore examines one of these possibilities by the development of Instruction Delivery Expert System for Teachers and also the need and benefits of the proposed expert system.
\end{abstract}

KEYWORDS: Information and Communications Technologies (ICTs), Expert System, Artificial Intelligence, Knowledge Base, Inference Engine, Working Memory.

\section{INTRODUCTION}

The essence of globalization is the simplification of complex human activities by providing alternative technology. Thus, Information and Communications Technologies (ICTs) education is having a revolutionary effect on educational methodology globally. However, this revolution is not widespread and needs to be strengthened to reach the large percentage of the population through the development of Instruction Delivery Expert System for Teachers (IDEST).

The use of technology in enhancing information delivery was one of the great achievements of Information and Communications Technologies (ICTs). Teaching process as a major process through which knowledge is impacted therefore needs a specific technology which should advance learning at least a step ahead of every other technology in existence. Since learning process is carried out by human, it is prone to some laxities as human can be affected by age, dead, sickness, etc. In a situation where such knowledge is not integrated and stored in an active storage and retrieval system or form, such knowledge may be lost or temporarily out-phase.

A specific technology such as expert system which is a branch of Artificial Intelligence (Al) has the capability of mimicking and acting exactly or even better than human professionals with little supervision by a professional. The expert system therefore is not a replacement of human experts as it does not have a $100 \%$ precision; it rather works with the essential control of its functionality by human experts.

The advantages of expert systems to human experts include:
$>$ Expert system is readily available round the clock

$>$ It is not perishable

$>$ It is usually faster in speed (especially in handling complex functions)

$>$ It can store and recall memory more easily

$>$ It has low running cost advantage, (Hausing, Lampert, and Rennhard, 2003).

A teacher as a chief executive of knowledge instruction delivery therefore needs this technology for instruction delivery. The essence of this technology (expert system) is to:

$>$ Conserve the knowledge of human teacher.

$>$ Provide help to lay men and experts in solving learning problems.

$>$ Make and provide instruction about learning available, especially those that are difficult to recall.

$>$ Provide alternative instruction delivery methods for teachers at various times pace (Hausing et al, 2003).

Expert systems work procedurally and precisely based on information stored on the knowledge base. Once learning (instruction delivery) procedures have been programmed into an expert system, it will not be easily influence by any other factors which is not part of the procedures of the program and thereby becoming a better instructor at the moment, delivering exactly what is expected and at the right time (Mockler and Dologite, 1992).

With the recent trends in technology, ICTs have provided alternative means of learning by enhancing the following:

I. E. Bassey, Department of Computer Science, Federal College of Education, Obudu, Cross River State.

E. E. Umoh, Department of Computer Science, Cross River University Of Technology, Calabar, Cross River State.

D. O. Egete, Information Technology Unit, University of Calabar Library, University of Calabar, Calabar, Cross River State 
$>$ Learning through projects

$>$ Impact of display technologies

$>$ Use of images for learning through review critique

$>$ Independent learning

$>$ The use of Personal Digital Assistants (PDAs)

$>$ Reflection on learners' product

$>$ Feedback through online assessment

$>$ Instant feedback through quizzes and quick test (ICTs Test Bed, 2007).

Training a professional teacher into enforcing the above becomes too complex to achieve, but building an expert system will be much more effective with low running cost and less control from the human expert (Professional ICTs base teacher).

This paper therefore discusses the possible ways to enhance ICTs education through the development of Instruction Delivery Expert System for Teachers and the need for the development of expert system to aid teachers in instruction delivery with the expectation that learning motivation facilities provided by ICTs will be better and effectively administered with the use of expert systems in instruction delivery by teachers.

\section{Expert System}

The aspect of technology that trying to converge parallel reasoning of human by using knowledge base to build a machine that mimic human in reasoning is Artificial Intelligence (Al) and expert system is a branch of Artificial Intelligence.

An expert system is a computer that possesses the knowledge and some of the common sense rules of an expert in a given field. It is thus able to arrive at original and intelligence-based solutions to problems in its domain, be it medicine, prospecting for minerals, diesel engine repair, chemical molecular analysis, electioneering process, instruction delivery, etc. (Jeffrey, 1985).

According to Ahmad (2005), expert system is an intelligent computer program that uses knowledge and inference procedures to solve problems that are difficult enough to require significant human expertise for their solutions. Expert System is designed to act in the capacity of an expert in various fields of expertise like teaching, engineering, commerce etc.

Expert system provides a more powerful and flexible means for solutions to variety of problems that often cannot be dealt with by other more traditional and orthodox method (Fairuz \& Zaiyadi, 2005). According to Fairuz \& Zaiyadi (2005) an expert system is a computer program that act as a "consultant" or "advisor" to decision makers which are comparatively cheaper to operate compare to human experts.

An expert system should help a novice, or partly experienced, problem solver, in the particular domain of problem solving that the system is designed to assist (Romiszowski 1986).

In respect to the view as observed by Romiszowski (1986), Expert system can be seen to be a veritable tool used in learning process as it can help a novice, an half experience learner or instructor in acquiring more skills in learning an instruction delivery. Also, area of learning that seems complex can better be handled by expert system aiding and increasing efficient delivery of instruction by teachers.

The only system that can conserve and recall knowledge stored in a knowledge base or what is popularly called database is an Expert System. The essence of transformation is the simplification of complex human activities by providing alternative technology (Bassey, 2009).

An expert system is designed to consist of user interface, through which control to the knowledge base could be made possible, inference engine, which is a module that deals with artificial reasoning, and knowledge base, which consists of rules, facts and experience (Romiszowskis, 1986). See fig. 1 below.

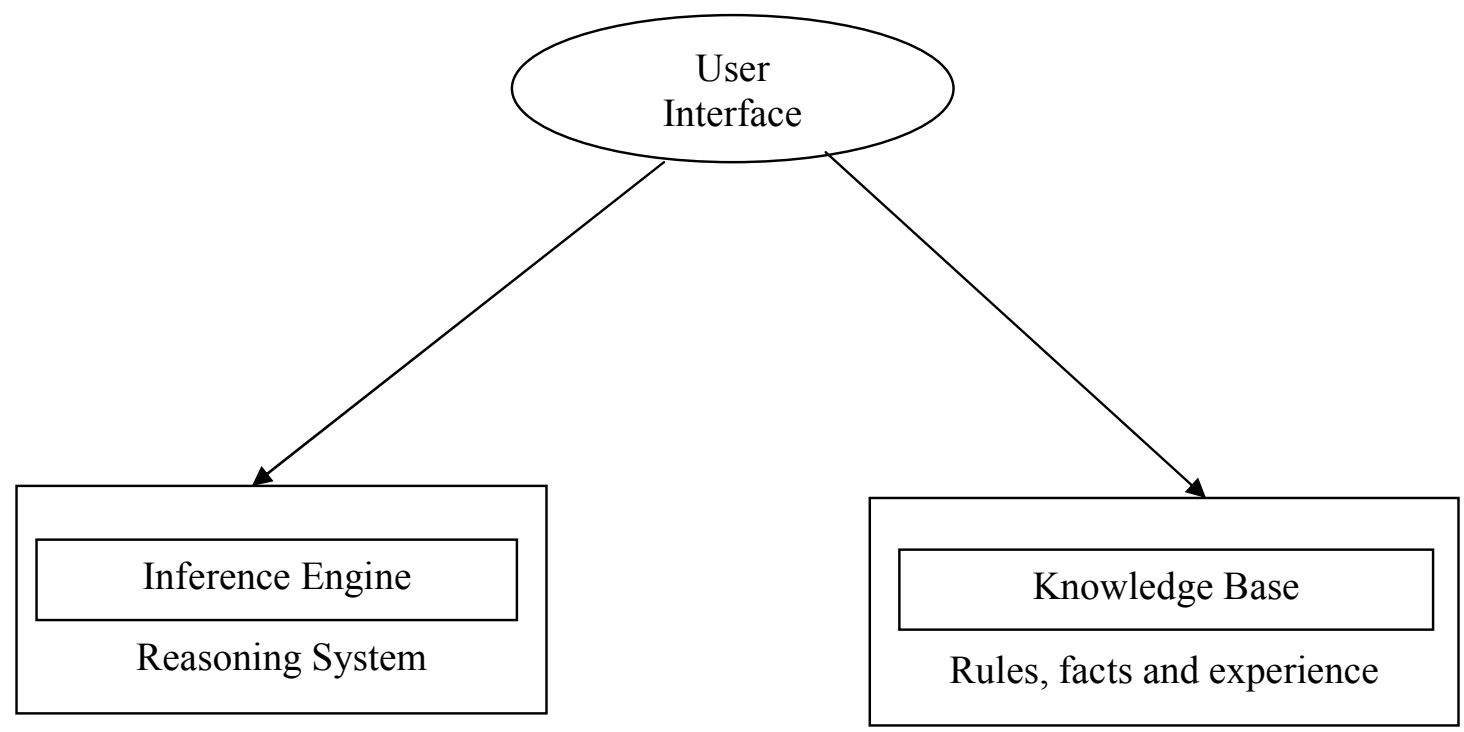

Fig 1: Simple Structure of an Expert System 
The knowledge base consists of expertise knowledge collected about a field or discipline integrated to form refined complete information which in most cases subject to update as there is improvement on day to day growth and development. The inference engine is built with series of rules that is used to manipulate the knowledge base accordingly to the demand functions and acts exactly as demanded.

\section{THE NEED FOR INSTRUCTION DELIVERY EXPERT SYSTEM FOR TEACHERS (IDEST)}

Expert system has been applied in many ways and various fields like education which are meant to make life of the students and teachers simpler (Basri, 1998). The application of expert system technology in the domain of education is particularly appropriate in order to preserve and disseminate efficiently valuable and scarce expertise in the field of teaching at low running cost (Basri, 1998).
Romiszowski (1986) considers the need for instruction delivery expert system as:

TOOL- Use by student to perform a task related to their course of study which is used in support of other learning/teaching activities, which in some cases becomes the integral parts of the instructional system.

TUTOR- The system takes on the teaching functions, presenting a series of screens or instructions, test questions and feedback, much as in program instruction, or involves the student in a simulation or game situations such as Computer Aided Learning (CAL), Computer Aided Instruction (CAI), etc.

TUTEE- The student teaches the system using a mode that enhance such communication like LOGO language which means, the student in programming is supposed to gain all manners of insight and powerful ideas of high transfer value (Papert, 1980).

Table1 below summarizing the use of expert system for instruction delivery by teachers:

\begin{tabular}{|c|c|c|c|}
\hline User & $\begin{array}{l}\text { 1. TOOL } \\
\text { commercially produced } \\
\text { expert system used to solve } \\
\text { problem (JOB AID) } \\
\text { Student learn by repeated } \\
\text { use }\end{array}$ & $\begin{array}{l}\text { 2. TUTOR } \\
\text { Intelligent computer assisted } \\
\text { instruction (ICAI) } \\
\\
\text { Intelligent database search } \\
\text { assistant (EMBEDDED } \\
\text { TRAINING) }\end{array}$ & $\begin{array}{l}\text { 3. TUTEE } \\
\text { Use of LISP or PROLOG } \\
\text { in schools. Student } \\
\text { instruct expert system for } \\
\text { the domain under study }\end{array}$ \\
\hline $\begin{array}{l}\text { Teacher/instruction } \\
\text { Designer/Author }\end{array}$ & $\begin{array}{l}\text { 4. Stand alone expert system } \\
\text { on instructional design, } \\
\text { decision making, planning, } \\
\text { controlling etc. }\end{array}$ & $\begin{array}{l}5 . \quad \text { Intelligent embedded } \\
\text { training in school applications } \\
\text { software }\end{array}$ & $\begin{array}{l}\text { 6. Teacher/subject matter } \\
\text { expert constructs expert } \\
\text { systems on specific } \\
\text { domains }\end{array}$ \\
\hline & Intelligent authoring & $\begin{array}{l}\text { Intelligent teacher training } \\
\text { systems }\end{array}$ & \\
\hline
\end{tabular}

Table1: Summary of the uses of Expert System for Instruction Delivery by Teachers

From Table1 above, it can be inferred that, a teacher can use expert system to aid as a tool, tutor or tutee.

Atkinson (2002) argues that what teachers know and do is the most important influence on what student learns; therefore the need to attract and train high quality teachers is widely recognized. From time passed, debate about the need to reform career structure for teachers has been on, hence, this is the time where the teaching profession should be harness with an active knowledge-base instructor (expert system), which will deliver adequately and effectively void of other biases as to human instructors. When instruction delivery process gets tougher, and the teacher finds it difficult to excel, the expert system designed to accomplish same task will glow and excel exceedingly (Atkinson, 2002).

The Institute of Technical and Adult Teacher Education (ITETE) in quest for excellence and the application of leading edge technologies introduced expert systems and education as a final semester option into their graduate diploma in educational studies during semester two of 1989 and it observed that the inaugural expert system option attracted majority of teachers, trainers and educators taking course in semester four of the graduate diploma in education programme. (Geddvod, 2003).

\section{DEVELOPMENT OF INSTRUCTION DELIVERY EXPERT SYSTEM FOR TEACHERS (IDEST)}

The Instruction Delivery Expert System for Teachers (IDEST) developed in this work is based on the current most popular choice of knowledge Engineering approach for building expert systems (that is rule-based expert systems) (Markham, 2001). The popularity of this kind of system design has grown up due to the large number of successful rule-based systems built and also the easy availability of rule-based expert systems software. Besides, rule-based expert systems are the representation of human being like natural reasoning, (Artificial Intelligence) and problemsolving paradigm. It models the human production system using the following modules as observed by Nazar \& Mohammed (2001). See fig 2 below for the structure of the rule-based IDEST. 


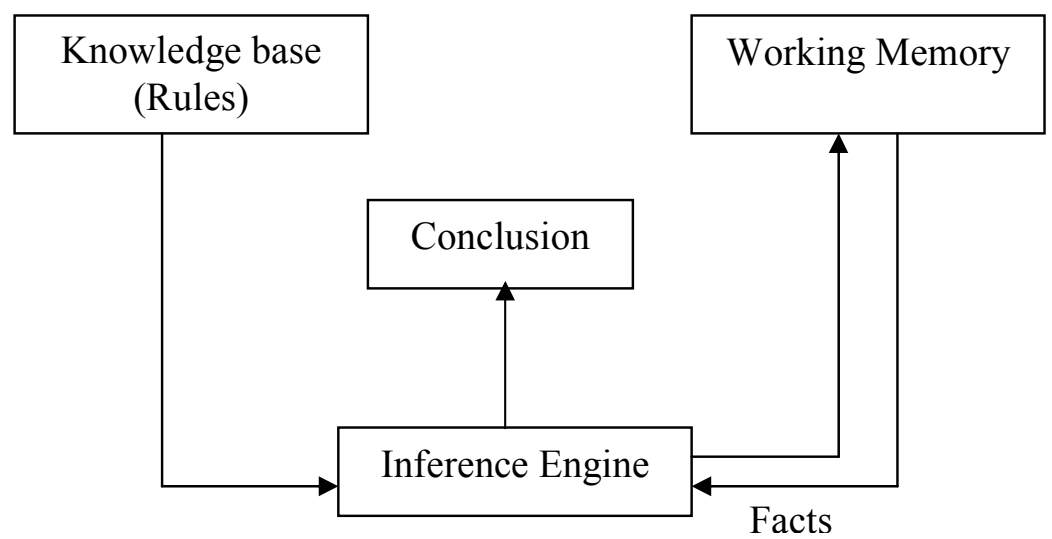

Fig 2: Rule-based IDEST

Knowledge Base: This models a human long term memory as a set of rules. The knowledge of the system is collected from expert teachers, specialized books, and from different teaching/learning websites. The knowledge base contained about 100 production rules for different types of instruction delivery approach by teachers.

Working Memory: This models a human short term memory and contains facts both entered and inferred by the firing of the rules.

Inference Engine: This models human reasoning by combining problem facts contained in the working memory with rules contained in the knowledge base to infer new information (Durkin, 1994).

The above techniques for the design were adopted because it can handle the numerous instruction delivery problems faced by some teachers which need different solution. Base on this concept of reasoning which emulate a human problem solving strategies, the expert system is structured according to the fundamentals of it. As used in the paradigm of problemsolving by the IDEST, the system have four basic elements which are adopted from the model of rulebased expert system (Working Memory, Inference Engine, Knowledge Base and User Interface) (Nazar \& Mohammed, 2001).

The model IDEST was implemented using $\mathrm{C}++$ programming language platform which is a forward chain rule-based language that resembles CLIPs and LISPs (Hubbard, 1996). The C++ programming language platform is chosen for the implementation of the proposed IDEST for four basic reasons:

- $\quad$ The data driven nature of the domain suggests the use of forward chaining inference procedure.

- $\quad \mathrm{C}++$ runs in windows environment which is the platform of choice among many end users.

- The availability of $\mathrm{C}++$ source code and

- The ability to construct production rules which depends on pattern matching.

It is expected that once the users log-in to the IDEST, they will be prompted with questions and answers according to the current lesson. The new information will be fed to the memory where then the system matches the information with the knowledge contents in the knowledge base to infer new facts about instruction delivery. The system therefore reaches the conclusion that is also entered into the working memory before displayed to the user through the interface.

\section{SIGNIFICANCE OF THE STUDY}

The aim of this research is to transform the expertise of the human expert into an automated expert system that can handle instruction delivery by teachers more efficiently and effectively.

It becomes pertinent to develop this system because of the tendency of teachers and students seeking for an effective and efficient means of teaching and learning more easily, timely, accurately and with less stress in institutions of learning.

The development of the system surely has some significance to humans, especially teachers and students. Among these are:

- The system will serve as a tool for the inexperienced teachers and it will improve their productivities. Having this system may allow teachers do more work in less time.

- The system will enhance effective instruction delivery by teachers and facilitate learning process because it can conserve the knowledge of experienced and professional teacher and recall the knowledge more easily than human experts, once programmed correctly using the desired knowledge base.

- It provides a systematic and intelligent method in instruction delivery by teachers.

- Finally, the study is significant as it is a pioneering effort using the concept of expert system to implement Instruction Delivery Expert System for Teachers (IDEST).

\section{BENEFITS OF THE PROPOSED IDEST}

The following shall be derivable from the implementation of the developed IDEST in this work.

- To improve instructional design and other teaching tasks.

- To improve the structure of knowledge and quality of instruction materials

- To enhance efficiency of embedded training

- To guarantee quality of CAI courseware

- To aid expert teachers in some routine task to improve productivity 
- To potentially serve as an effective, efficient and viable educational aid in learning and teaching

- $\quad$ To conserve the knowledge of an experienced and professional teachers (human experts).

- To aid teachers in some difficult tasks to effectively and efficiently manage complexities

- To make information available that is difficult to recall

- $\quad$ To provide enabling environment for learners and experts in solving problems

- To save time and eliminate distance barrier in learning and teaching.

However, the IDEST is not the replacement of human experts with a computer system rather is an aid to enhance and increase efficiency and the productivities of human experts.

\section{CONCLUSION}

Having ascertained the fact that expert systems can do exactly what a human expert can do and even better at a considerable running cost advantage and also overcoming factors militating against human experts such as dead, fatigue, time, etc, it becomes expedient for the incorporation of this dynamic system in the teaching professions where the bed rock of knowledge is pivotal and to ensure effective use of ICTs for education services especially instruction delivery by teachers.

We believed that expert system technology has great potentials to enhance ICTs education that will assist Nigeria to achieve education for all by the year 2020 and therefore should be maximally harnessed by all possible avenues.

The proposed IDEST in this work has the features of good expert systems, such as high performance, adequate response time and understandability and therefore hoped to go a long way achieving the expectation and demands placed on the educational sector.

\section{REFERENCES}

Ahmad, T. A., 2005. An Expert System for Car Failure Diagnosis. Proceeding of World Academy of Science, Engineering and Technology 7 (1): 457-460.

Atkinson, R., 2002. Australia's Teachers need a System of Training and Professional Development. http://cleo.murdoch.edu.au/gen/asset/ajet3/wi87 p6.html.

Basri, H., 1998. An Expert System for Planning Land Fill Restoration. Water Science and Technology. 37(8), 211-217.

Bassey, I. E., 2009. "An Expert System for Troubleshooting Automobile Engine Faults".
Unpublished M.Sc. Thesis, Department of Computer Science, Ebonyi State University Nigeria.

Durkin, J., 1994. Expert System Design and Development. New York, Macmillan Publishing Company.

Fairuz, M. and Zaiyadi, B., 2005. Expert System for Car Maintenance and Troubleshooting. Generation 5. http://www.generations.org/content/2005/carmai ntenance.asp.

Geddvod, G., 2003. Expert Systems and Education: An Innovation in Grad Dip Ed (Computer Education).

http://itech/coe.edu/Epss/whatis.html.

Hausing, M., Lampert S. and Rennhards, M., 2003. Network Troubleshooting Expert System. Diploma thesis (Unpublished)

Hubbard T.R., 1996. Theory and Problems of Programming with $\mathrm{C}++$. New York, McGrawHill.

ICT Test Bed, 2007. The Role of ICT in Enhancing Learning and Assessment http:/www.evaluation.icttestbed.org.uk

Jeffrey, R., 1985. Minds over Matter: A New look at Artificial Intelligence. Great Britain: The Camelot Press.

Mockler, R.J. and Dologite, D.G., 1992. KnowledgeBased System. An Introduction to Expert Systems. New York, Macmillan.

Markham, H. C., 2001. An Internet Based Expert System for Teaching Introductory Data Structures: Proceedings of the Seventh Annual Conference for Computing in Small Colleges Central Plains. Conference on the Journal of Computing of Small Colleges 27(5): 155-165.

Nazar, M. Z. and Mohammed, D., 2001. Development of Computer Aided System for Environmental Compliance Auditing. Journal of Theoretic 7(1): 44-49.

Papert, S., 1980. Mindstorm: Children, Computers and Powerful Ideas: New York: Basic Books.

Romiszowski, A. J., 1986. Developing Auto-instructional Materials: From Programmed Texts to CAL and Interactive Video. London, Kogam Page 